algebra of the utmost simplicity, which a child (if he were thus sophisticated) could understand, and to a notation of great beauty, because it conveys what it says. When one thinks of all that Russell went through sixty years ago, to write the Principia, and all we his readers underwent in wrestling with those three vast volumes, it is almost sad. All credit to Russell, then, who endorses this book with his congratulations.

Publishing this review at all is almost a nonsense: you would be better employed in reading the book itself, for Spencer Brown tells his own story in a way that defies exegesis. I would as soon give an account of a sonnet. Here is mathematics being created in front of our very eyes. My own suspicion is that we are also observing the creation of a science of design, and the laying down of a proper basis for a new epistemology. It is very difficult to say at such close range. Whatever the author is doing, he is doing somcthing remarkable-of this I am very sure. And this would remain true, although somebody should succeed in uncovering defects that I have not observed.

I very much hope, for the sake of their own delight, that those who have thought hard about the nature of mathematics, of logic, of the thinking process, or of the universe itself, will read this book. It would be impertinent for me to try to offer a final judgment here. Yet every experience can be placed decisively on one side or the other of a valid distinction, the real meaning of which is not at all the point. So teaches Spencer Brown himself: "Distinction is perfect continence". The existence of this book draws a distinction; I leave no room to doubt on which side of that distinction my experience lies.

STAFFORD BEER

\section{STOCHASTIC APPROXIMATION}

\section{Stochastic Approximation}

By M. T. Wasan. (Cambridge Tracts in Mathematics and Mathematical Physics, No. 58.) Pp. x+202. (Cambridge University Press: London, June 1969.) 70s; $\$ 9.50$.

IT has been said (and if it has not, it could have been) that current statistical journals contain a large number of mathematical results looking for real problems. One such series of results concerns stochastic approximation, the generalization into a statistical framework of the iterative proccdures used in numerical analysis for the solution of equations. In the literature, examples of how such methods work in practice are in short supply, and it was therefore exciting to read in the preface to this book that the author had "collected a number of applications of stochastic approximation to problems in engineering and medicine" and had also "shown how one can make use of these techniques in practice". How disappointing to find that the number is only four (process control, the joint action of drugs, an optimum inspection procedure for a repairable system and the estimation of quantal response); particularly because the last is probably better dealt with by the up-and-down method (also covered in this book), which is, strictly speaking, not stochastic approximation at all. The distinction here lies in the fact that stochastic approximation is concerned with sequential procedures which converge to the quantity one is trying to measure; the up-and-down method is a sequential method designed to select in an optimum way the levels at which a quantal response experiment is performed. It would be possible to read this book without becoming aware of this distinction.

These remarks could be construed as criticism if this book were claimed to be about statistics. They should not be. It is, after all, in a mathematics series and must be judged as mathematics. In it the present state of the mathematics of stochastic approximation is covered with care, rigour and accuracy. It is written in the fashionable mid-Atlantic style with (even in the practical applications) definitions, theorems and remarks suitably displayed and following one another in unceasing succession: a reader with reasonable mathematical competence wishing to use the method discussed could well start here. It is, however, only one side of the story. The statistician who remembers his first attempt at, for example, using an iterative procedure to obtain maximum likelihood estimates in a multi-parameter situation will suspect that the practice is not so straightforward as the theory suggests.

F. Down'Ton

\section{RUMFORD ON HEAT}

The Collected Works of Count Rumford

Vol. 2: Practical Applications of Heat. Edited by Sanborn C. Brown. Pp. viii + 523. (Harvard University Press: Cambridge, Massachusetts; Oxford University Press: London, June 1969.) 95s.

THE new edition of Rumford's collected works, the first volume of which was reviewed not so long ago (Nature, 222, 800; 1969), proceeds with commendable speed. We are now presented with the second volume, which largely describes Rumford's practical applications of the physical principles about heat production and convection which he had discovered. There are still a few papers of more fundamental character, related to the convection of heat, which had not found a place in the first volume. The pièces de résistance are the extensive treatises "Of Chimney Fireplaces" (1796) and "Of the Management of Fire and the Economy of Fuel" (1798), the sound principles of which have not yet been completely assimilated by the English building tradition.

L. Rosenfeld

\section{RADIATION HAZARDS}

\section{Chemical Applications of Radioisotopes}

By H. J. M. Bowen. (Methuen's Monographs on Chemical Subjects.) Pp. xi+131. (Methuen: London, June 1969.) $30 s$.

Methuen's monographs have a reputation of high quality. They usually provide authoritative information at a low price, a virtue rarely found in the modern publishing world. But this reputation confers a responsibility on the publishers and editors of this series which I feel was not adequately taken on a small but very important point in this book. The treatment of the health hazards of ionizing radiations is lacking the serious approach it deserves. I consider it a great danger to start the only and very brief mention of the health hazards involved in handling radioactive isotopes by writing:

"Hazards to health often loom large in the imaginations of intending users, but as far as tracer work is concerned they are rarely more serious than the hazards involved in handling chemicals such as concentrated sulphuric acid, arsenic or potassium cyanide."

A few sentences later this statement is supplemented by some rules concerning "Handling radioactive isotopes for any hazardous chemicals)". The rules are commonsense chemical laboratory rules and not those laid down by law in many countries. The next few pages are devoted to physical applications of tracers. Examples include, for instance, the burying of $200 \mathrm{mCi}$ of ${ }^{60} \mathrm{Co} 1$ metre below ground to mark the position of pipes, or the leak testing of vacuum lines by "squirting with a jet of tritium gas on suspected leaks" and looking for radioactivity in the vacuum lines. Both techniques suggested could lead to serious health hazards when applied by the novice and to concomitant transgression of the law. 